\title{
A framework for ICT-enabled real-time production planning and control
}

\author{
Emrah Arica $\cdot$ Daryl J. Powell
}

Received: 5 February 2014/ Accepted: 25 March 2014/Published online: 11 April 2014

(C) Shanghai University and Springer-Verlag Berlin Heidelberg 2014

\begin{abstract}
This paper aims to develop a conceptual framework for real-time production planning and control (PPC). Firstly, we discuss the most prominently applied contemporary information and communication technologies for PPC. Enterprise resource planning (ERP) systems that integrate the value chain in an enterprise, manufacturing execution systems that manage and control the production on shopfloor, and advanced planning and scheduling (APS) systems that develop solutions for complex planning problems are the planning and control systems that have been analyzed. We emphasize the application of radio frequency identification as the most advanced and promising emerging real-time data capture technology that is currently available to manufacturers. Having analyzed the features and shortcomings of the individual systems perse, and by considering the advantages that may be realized through effective integration of these otherwise discrete systems, we propose a framework for real-time PPC.
\end{abstract}

Keywords Enterprise resource planning (ERP) . Manufacturing execution systems (MES) · Advanced planning and scheduling (APS) - Radio frequency identification (RFID) · Production planning and control (PPC)

\section{Introduction}

The future demand driven factory will be based on intelligent and automated planning and control systems,

E. Arica · D. J. Powell $(\bowtie)$

Department of Production and Quality Engineering, Norwegian

University of Science and Technology, Trondheim, Norway

e-mail: daryl.j.powell@ntnu.no employing closely integrated real-time information systems throughout the entire supply chain. This will enable the manufacture of customized products within highly responsive, reconfigurable, and time efficient environments, as well as effective and robust planning for standardised products. However, we foresee a number of obstacles which need to be overcome in order to achieve a demand driven value chain.

The purpose of this paper is to evaluate current enterprise systems and technologies and analyse their limitations in order to present a conceptual framework for realtime production planning and control (PPC). This paper considers PPC systems at the individual plant level and reflects on integration within the supply chain through the application of contemporary and emerging information and communication technologies (ICTs). We suggest that such integration will subsequently enable a more effective realtime PPC process.

We investigate the level of automation within enterprise resource planning (ERP) systems and discuss the impact of human interaction with ERP systems, as the quality and accuracy of data input is considered a current weakness with today's ERP systems. The concept of advanced planning and scheduling (APS) is also explored. Furthermore, the interaction of ERP systems with manufacturing execution system (MES) and the prevailing shortcomings are discussed. By considering radio frequency identification (RFID), we also explore the utilization of real-time data within the supply chain, the production planning function, and the shopfloor. On the basis of these functions, existing shortcomings, and the capabilities of combining the otherwise discrete systems, we propose a framework that integrates ICTs for real-time PPC.

The paper is structured as follows. We first address the ICT systems which can be utilized for automated PPC. 


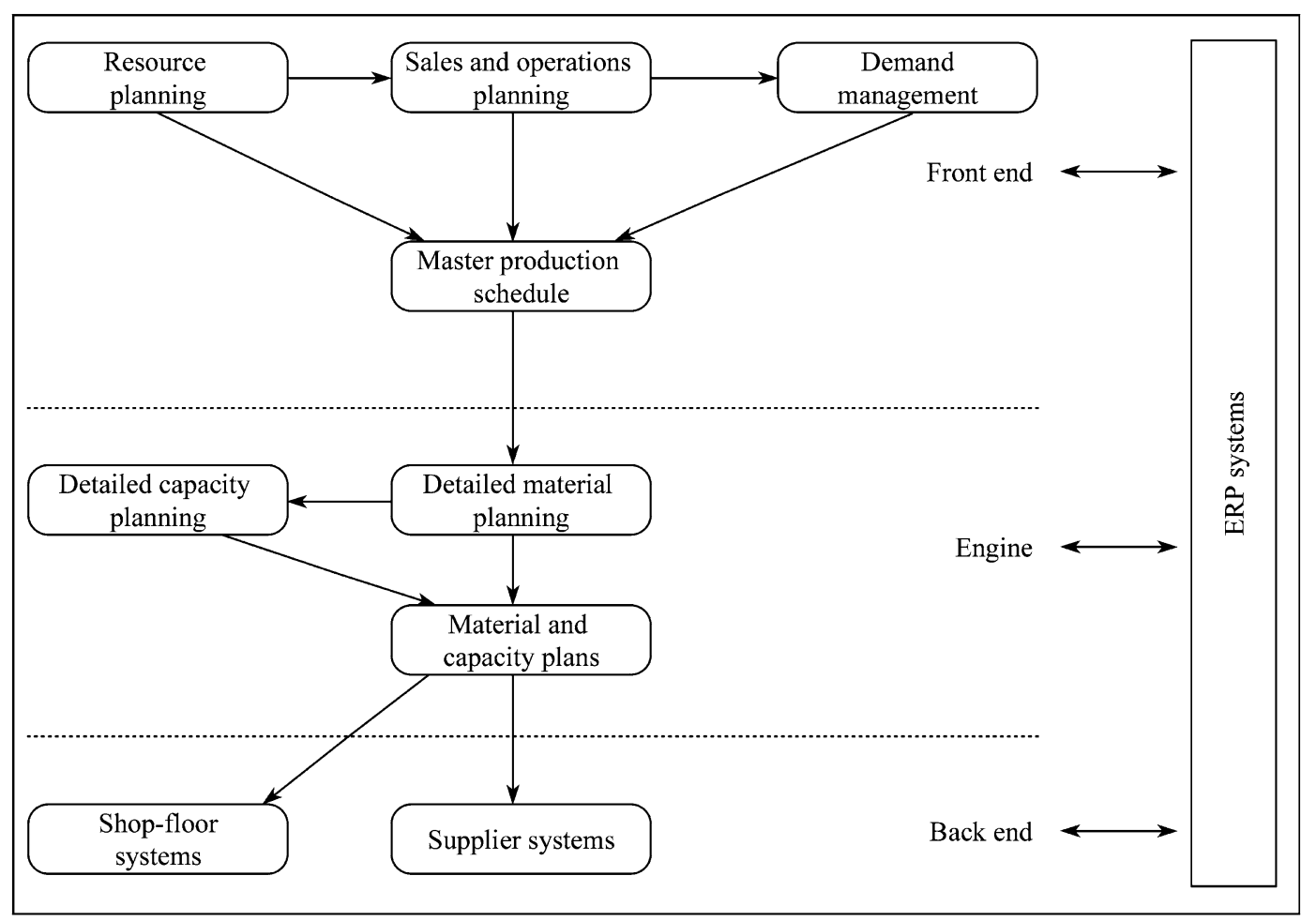

Fig. 1 ERP systems for manufacturing planning and control [5]

Next we consider real-time information systems, introduce and discuss relevant applications of RFID. Then we discuss and present a conceptual framework for real-time PPC, which combines and further integrates enterprise systems with real-time information systems. Finally, we draw conclusions to this research, and identify areas for further work.

\section{Contemporary planning and control systems}

With the advances of communication and integration standards, data processing capabilities, network computing and internet technologies, the computerization pace in a manufacturing enterprise is accelerating so that the enterprise can provide a better customer service level with higher productivity, higher quality, and lower inventory costs. As such, many manufacturers are implementing advanced ICTs to support manufacturing operations. This section reviews the state-of-the-art in terms of applied PPC systems.

\subsection{ERP systems}

The majority of manufacturing firms today use ERP systems to develop medium-term and short-term production plans and schedules [1]. ERP is a standardized software package designed to integrate the internal value chain of an enterprise [2]. According to Ref. [3], the American Production and Inventory Control Society (APICS) defines ERP as "a method for the effective planning and control of all resources required to take, make, ship and account for customer orders in a manufacturing, distribution or service company".

However ERP systems remain centred around old material requirements planning (MRP) logic in many cases, capacity constraints continue to be neglected and lead that times are still assumed to be fixed. This creates many problems for the shopfloor [4]. With a typical MRP-based planning system, there is no guarantee that a feasible production schedule exists for the generated production plan. This results in constant adjustments to the plan, and drives planners to lengthen "standard" lead times and increase work-in-process (WIP) inventories (see Fig. 1).

Much like ERP systems and the hierarchy of PPC, the planning and scheduling of a supply chain also occurs in various phases: a first phase involving the medium-term planning process (using aggregated data), and a subsequent phase performing a more detailed, short-term schedule [6].

\subsection{APS systems}

Although ERP systems provide an information backbone that is needed for sound planning procedures, there is still a 


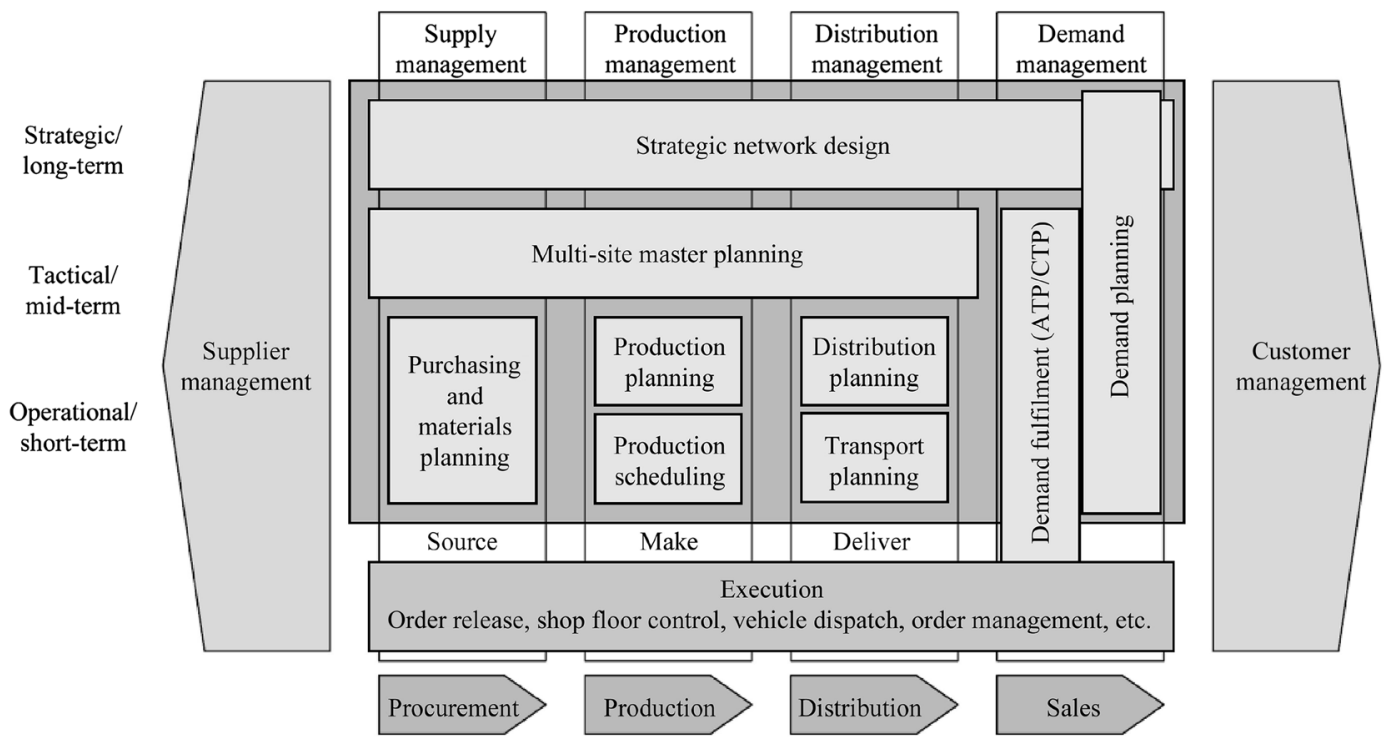

Fig. 2 Typical APS planning structure [13]

lack of intelligent planning and decision support functions. This has led to the development of so-called APS systems. APS emerges to supplement the ERP systems and eliminates some of the major MRP assumptions such as fixed lead times [7].

Kjellsdotter and Jonsson [8] suggest that APS is supposed to help companies deal with more complex planning situations. Kletti [9] refers to ERP-based planning as rough planning, and suggests that the use of APS allows for socalled detailed planning. Whereas ERP systems are typically transaction-orientated (i.e., sale invoices, shipment notices, etc.) and have limited decision support features, an APS system leverages the data within the ERP system to provide decision support for both production planning and demand planning [10].

By considering the most common standard APS modules in Fig. 2, it is apparent that APS is perhaps more applicable to planning and scheduling the entire supply chain or network rather than purely within a single production plant. It is clear from Fig. 2 that production planning and production scheduling comprise only one module of the APS system, which makes ERP a central part of the APS. As such, Jonsson and Kjellsdotter [11] reflect that APS systems are potential support tools for managing complex supply chain planning problems and as a mean for supply chain integration. On the other hand, in the context of the individual plant, Fleischmann and Meyr [12] suggest that the real advance with APS is the implementation of advanced planning concepts in standard software, which is a great progress in comparison to traditional ERP systems.

When combined with ERP systems, APS allows for explicit, capacity constrained PPC. It considers not just shopfloor capacity constraints, but also inventory and bill of material constraints, inventory stocking and replenishment levels, and order generation policies [14]. However, Jonsson and Mattsson [15] state that although APS methods offer concurrent priority and capacity planning, the level of application of APS is still low in industry. A comprehensive study by Ivert [16] regarding the use of APS systems in different planning and control tasks also supports this view.

\section{$2.3 \mathrm{MES}$}

MES has evolved to aid production execution, monitoring, and control activities on the shopfloor, overcoming the drawbacks of the ERP systems in real-time information exploitation from the shopfloor. An MES controls the operations that enable the realization of the plans from the ERP system. MES systems have initially been implemented in process industries (e.g., pharmaceutical, food, and semiconductors) for traceability purposes imposed by authorities, but are currently in use in most types of manufacturing industry [17].

The Manufacturing Execution Systems Association [18] defines the principle functionalities of MES, as shown in Fig. 3. Additionally, depending on the process type and shopfloor requirements some MES vendors may offer extended functionalities such as engineering change management, rework management, outsourced manufacturing.

\subsection{Key limitations with contemporary planning and control systems}

Though the enterprise systems described in this paper can be classified as automated planning and control systems to a certain degree, they still require a large amount of human 

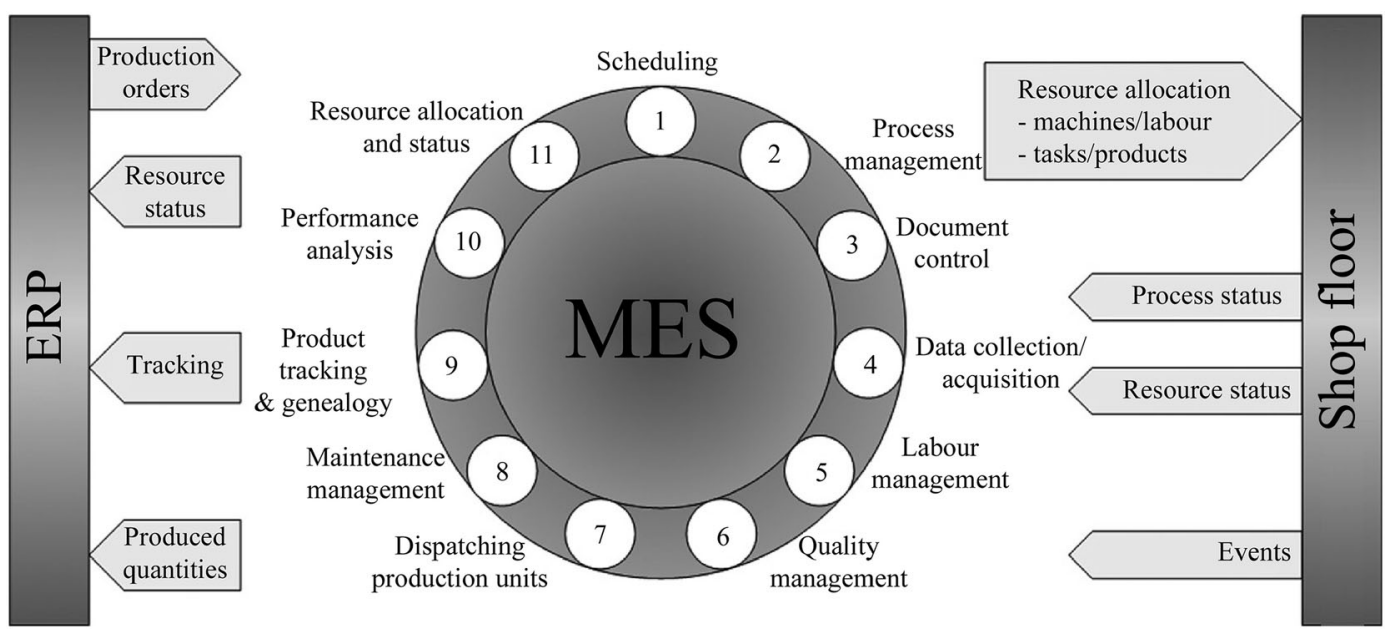

Fig. 3 MES functionalities [17]

interaction in order to work properly. For example, a PPC system cannot function effectively when the enterprise system is driven by inaccurate, untimely and uncontrolled data. Poor input data will lead to excessive replanning and rescheduling, which is both costly and disruptive. Xu et al. [19] support this view by suggesting that when organizations implement an ERP system, it is imperative that data quality issues are a high priority. Such a simple, yet vital task as data entry into an enterprise system becomes the point of failure, resulting in synchronization issues, loss of data and other potential risks.

ERP systems are mainly intra-firm focused, which provide seamless integration of processes delivering improved workflow, standardized business processes, improved accounting and up-to-date operational data [20]. Though this sounds good in theory, in practice, it can be very different. For example, standardized business processes may be challenged across functional boundaries, and the up-todate operational data may, in fact, not be so up-to-date after all. Several organizational boundaries are introduced when attempting to push the enterprise system out across the supply chain, and suddenly these problems increase exponentially.

Jonsson and Mattsson [21] discuss the results of a longitudinal study into the use of material planning methods in manufacturing companies, which they conducted between 1993 and 2005. One conclusion they made is that a typical way of determining parameters used in ERP systems (for example order quantities and safety stocks) is by general judgment and experience. Thus, rather than using the ERP system to calculate and propose intelligent and efficient order quantities and stock levels, the planner typically overwrites this function with his or her best guess.

There is still lack of information availability in shopfloor. For example, an ERP system alone lacks the functionality to offer detailed visibility into the manufacturing work flow and information on individual critical resources, such as machine and tooling status, WIP levels and the location of products in the production processes in order to support intelligent, dynamic decision making as unexpected events occur.

The major contributions of the MES in the shopfloor control context are: sensing the unexpected events during production execution, elementary data storage, restitution of the data and relevant data selection [17]. However, the contribution of the other information systems and decision support tools is also important to complete the process and respond the changes effectively. In this context, MES may especially lack decision making capabilities to evaluate the unanticipated situation and suggest corrective actions, which for example can be supported by APS if the data are timely and accurately provided.

Accurate lead times and safety stocks are two of the most critical parameters for achieving high planning and control performance [15]. By using real-time information technologies integrated within an ERP-MES-APS infrastructure, the accuracy of such parameters will be increased substantially. Furthermore more precise and accurate plans can be developed.

With the recent development of ISA95 standard, the enterprise-control systems integration has been made easier to achieve. The standard defines a general model for manufacturing operations and planning levels that can be mapped into systems such as ERP, MES, APS, and product data management (PDM) [22]. Hence, it facilitates the real time data access across manufacturing operations. More specifically it defines

(i) the information exchange between business functions and manufacturing operation functions; 
(ii) the interfaces and data flows between associated control systems (e.g., ERP and MES);

(iii) the interface contents between the systems.

\section{Real time data capture}

Traditionally, data collection has been a very manual process, at best using simple technologies in the form of barcode readers to track inventory movement and shopfloor activities. There is now a general belief within industry that capturing and sharing real-time demand information is the key to improve supply chain performance [23].

Real-time information capture can be described as the capability of obtaining the required information at the required time from intended objects, devices or people by data capture technologies [24]. This enables people to monitor the tracked entities and have rapid and efficient responsiveness to change in their conditions.

Real-time data acquisition technologies make the enablers to have the availability of real-time information. RFID is currently the most advanced technology in realtime data capture and has been gaining popularity increasingly in the last decade in any place requiring identification of products [25]. It enables people to track items of interest and obtain necessary information such as identity, location, movement and states of them, and to manage the supply chain of goods more effectively, accurately and automatically.

RFID offers some significant advantages against other data capture technologies [24, 25]. These are: (i) no line of sight is required, as such they are suitable to communicate from a long distance; (ii) RFID tags can be positioned on common materials easily without confronting with any incompatibility; (iii) automatically captured highly accurate data; (iv) information is captured in seconds; (v) RFID tags contain more information.

\subsection{Applications in the supply chain and on the shopfloor}

The application and potential benefits of auto-ID technologies within the supply chain have been widely investigated, reported and recognized by both research and business environments [26, 27]. Considering supply chain performance measures at the production level, such as range of product and services, capacity utilization and effectiveness of the scheduling techniques [28], it is clear that minute-by-minute control on the manufacturing system will significantly contribute to the improvement of these measures, and as a result to the performance objectives of supply chain management. Slack et al. [29] state that capacity utilization affects the speed of response to customer demand through its impact on flexibility, leadtime and deliverability.

However there is a substantial need for research within the manufacturing applications [30]. Manufacturing environment includes many operational issues such as production and inventory management and maintenance as well as embodies plenty of objects including machines, tools, raw materials, WIP, finished products, reports, production plans and schedules, drawings, instructions, etc. However most of the modern shopfloors have a bottleneck of capturing and collecting real-time information from the field as well as to exploit this information in their manufacturing planning and control systems. RFID technology is a promising and emerging technology to deal with this challenge and can contribute to improve shopfloor productivity and quality [31]. RFID tags will be significantly beneficial and provide the factories with minute-by-minute coordination of raw materials, WIP and finished goods as they serve as means of effective data collector and processor. When a fault appears in the process, reflecting on that the problem will be rapidly performed and decisions will be taken on time without losing the precious time in production.

Tremendous pressure of current competitive market conditions resulting in heading towards to demand driven manufacturing approach, RFID adaptation has also a lot to promise to manufacturers to overcome customization challenges within the manufacturing process. In this competitive environment, companies must shorten product life cycles, reduce time-to-market, increase product variety and satisfy demand while maintaining the quality standards and reducing investment costs [32]. Brusey and McFarlane [33] express that application of sophisticated RFID technology has potential to solve the tracking problem of customized products in even late assembly process of the customization competence. As each product ordered by a specific customer has different specifications, such a system that integrates with the manufacturing control system and obtains very accurate information about the location, state and identity of each product is critically important to avoid highly possible problems and delays.

\section{Implications and discussions for real-time PPC}

The required system is supposed to sense any event occurring on the shopfloor and collect real-time data, analyze, and reflect upon it automatically within the planning system. In addition to these capabilities the system should synchronize the objectives of tactical level planning (ERP-supply chain) with the production plans on the 
shopfloor (e.g., MES). Basically this important issue is not being considered comprehensively, therefore operational level goals do not conform to those of tactical level. As a consequence, strategic and tactical goals cannot be accomplished to the desired level as things get much more complicated down on the shopfloor when the production plans are broken down. Only focusing on solving the problem at the supply chain level (sale and operation plans) or on the shopfloor level (production planning, scheduling and execution) is not sufficient to overcome the challenges that occur due to the uncertain and demand driven environment. Thus the system should optimize the tactical and operational level plans simultaneously.

The first task in real-time PPC is collecting and utilizing the data on a real-time basis. The data collection from the shopfloor must adopt an autonomous functionality, which implies the deployment of real-time technologies to the relevant objects. Integrating the real-time information system, and synchronizing it with the enterprise system, transmitting this information to the business functions and processing it will provide the organization with a highly adaptive and responsive planning and control system. It is of high importance to effectively deal with the real-time data in the organization in order to utilize it in the planning, scheduling and execution system. Having the ability of real-time control on the shopfloor events is crucial to have the capability of recognizing deficiencies before losing time and reflecting on it. This capability will prevent the potential failures and troublesome issues in other parts of the supply chain. Moreover, such efficient and effective shopfloor control grows in importance for high responsiveness to changes such as customer requirements since it is one of the key enablers to have a flexible manufacturing system. RFID system deployment to the shopfloor objects and connection with the MES through wireless technologies will provide this ability.

An MES executes the production on the shopfloor. It detects, follows and analyzes the machine run and stop times, cycle time, number of scrap units as well as orders on real-time basis. Furthermore the system can dispatch the jobs to the machines, calculate the efficiency and actual machine capacities precisely and report it. Sending accurate information from manufacturing environment to the ERP system efficiently increases the visibility and control on manufacturing execution which is one of the black boxes for supply chain control. As the ERP system provides information transparency through the supply chain, fully integrated ERP-MES system offers high coordination of the manufacturing processes across the supply chain and increases the responsiveness to constant changes that occur in both customer and supply side. Having the availability of accurate data also leads to increase the performance of plans in ERP and MES. Nevertheless, in order to improve

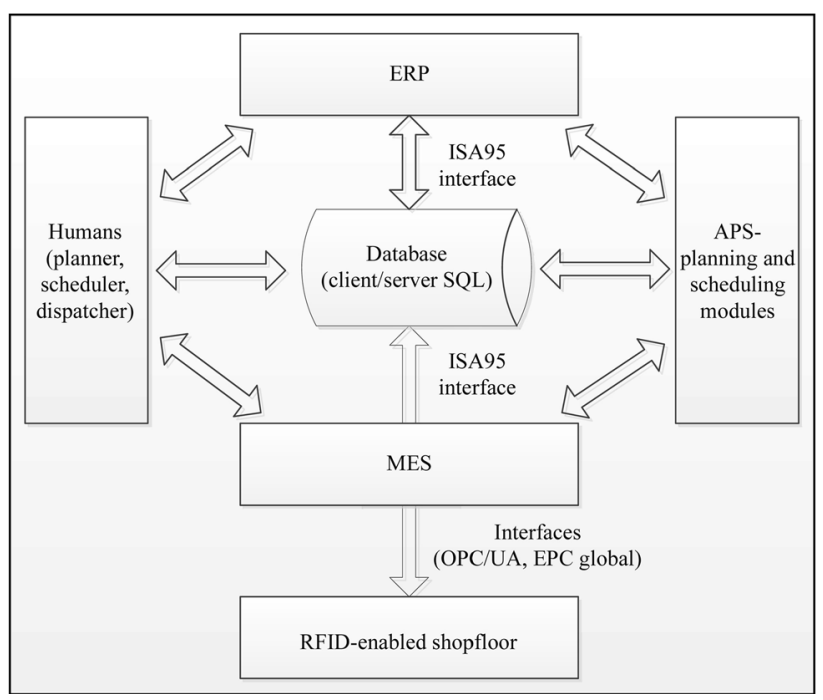

Fig. 4 Framework for ICT-enabled real-time PPC

the decision making process by real-time capability, there is strong need for interface between the ERP and MES systems that integrates them, utilizes the masses of realtime data, reduces the manual work and automates the data transfer (see Fig. 4).

Integrating MES-ERP with the APS system can lead to substantial improvement in production plans. MES can detect and analyze actual shopfloor constraints (e.g., machine capacity, efficiency, changeover time, etc.) precisely. Having this information available in the APS system along with supply chain constraints and transaction data coming from the ERP system can significantly contribute to develop advanced and accurate production plans by the APS system on real-time basis. Furthermore, the APS system can also develop a complex bi-objective model for tactical and operational plans and optimize it by taking their constraints and objectives into account simultaneously. This capability also contributes to integrate the supply chain with the shopfloor. Thus, it is suggested that MES-ERP-APS integration equipped with real-time information technologies can support the manufacturers to perform the PPC process on an automated and real-time basis and accurately.

\section{Conclusions and further work}

Automatic real-time planning and control systems promise substantial advantages to manufacturing companies, especially those that operate within fluctuating and competitive market conditions within a demand-driven manufacturing environment, since flexibility and robustness of the planning and control system are the inherent enablers for a high 
level of responsiveness in this type of industry. Integrating a real-time information system and synchronising it with the enterprise system, transmitting this information to the business functions, and processing it to enable rapid decision-making processes will provide the organization with a highly adaptive and responsive planning and control system.

However, before the implementation of such a revolutionary, demanding, and potentially expensive system that requires radical re-organization within a company and its supply chain, as well as dynamic interaction between operational shopfloor level decisions with enterprise planning and execution systems, the system architecture requirements, expected benefits, motivations and purposes to adopt such technologies, as well as the characteristics of the pilot company, should be investigated very carefully. Since the technologies (ERP, APS, MES, RFID, etc.) contain some challenges and shortcomings themselves, and synchronization with current enterprise systems poses even more difficulties, it is crucially important to develop solutions before the seamless integration of such a realtime planning and control system can be employed. Thus, we suggest that the further work is required in order to operationalize and test our conceptual framework in a number of use cases through determining a set of critical performance objectives at both a tactical and operational level. A subsequent impact analysis of the framework on the identified objectives should also follow.

Acknowledgments The authors would like to acknowledge the support of the research program SFI NORMAN (Norwegian Manufacturing Future) which provided the funding for this research.

\section{References}

1. Stevenson M, Hendry L, Kingsman B (2005) A review of production planning and control: the applicability of key concepts to the make-to-order industry. Int J Prod Res 43:869-898

2. Møller C (2005) ERP II: a conceptual framework for next-generation enterprise systems? J Enterp Inf Manag 18:483-497

3. Nah FFH (2002) Enterprise resource planning solutions and management. IGI Global

4. Chen K, Ji P (2007) A mixed integer programming model for advanced planning and scheduling (APS). Eur J Oper Res 181:515-522

5. Jacobs FR, Berry WL, Whybark DC et al (2011) Manufacturing planning and control for supply chain management. APICS/CPM Certification Edition, USA

6. Kreipl S, Pinedo M (2004) Planning and scheduling in supply chains: an overview of issues in practice. Prod Op Manag 13(1):77-92

7. Steger-Jensen K, Hvolby HH, Nielsen P et al (2011) Advanced planning and scheduling technology. Prod Plan Control 22:800-808

8. Kjellsdotter L, Jonsson P (2008) Prerequisites for using APS in S\&OP and MPS processes. In: Proceedings of the EurOMA conference 2008
9. Kletti J (2007) Manufacturing execution systems (MES). Springer, Berlin

10. Kilpatrick J (1999) Advanced planning systems spark the supply chain. Apics Perform Adv 9:24-29

11. Jonsson P, Kjellsdotter L (2007) Applying advanced planning systems for supply chain planning: three case studies. Int J Phys Distrib Logist Manag 37:816-834

12. Fleischmann B, Meyr H (2003) Planning hierarchy, modeling and advanced planning systems. Handb Op Res Manag Sci $11: 455-523$

13. Stadtler H, Kilger C (2008) Supply chain management and advanced planning: concepts, models, software, and case studies. Springer, Berlin

14. Turbide D (1998) Advanced planning and scheduling (APS) systems. Midrange ERP Mag 1

15. Jonsson P, Mattsson S-A (2008) Inventory management practices and their implications on perceived planning performance. Int $\mathrm{J}$ Prod Res 46:1787-1812

16. Ivert LK (2012) Use of advanced planning and scheduling (APS) systems to support manufacturing planning and control processes. Dissertation, Chalmers University of Technology

17. De Ugarte BS, Artiba A, Pellerin R (2009) Manufacturing execution system - a literature review. Prod Plan Control 20:525-539

18. MESA (1997) MRP to MES data flow possibilities. MESA Interna

19. Xu H, Nord JH, Brown N, Nord GD (2002) Data quality issues in implementing an ERP. Ind Manag Data Syst 102:47-58

20. Mabert VA, Soni A, Venkataramanan M (2003) Enterprise resource planning: managing the implementation process. Eur $\mathrm{J}$ Oper Res 146:302-314

21. Jonsson P, Mattsson S-A (2006) A longitudinal study of material planning applications in manufacturing companies. Int J Op Prod Manag 26:971-995

22. Campos JG, Miguez LR (2011) Standard process monitoring and traceability programming in collaborative $\mathrm{CAD} / \mathrm{CAM} / \mathrm{CNC}$ manufacturing scenarios. Comput Ind 62:311-322

23. Cachon GP, Fisher M (2000) Supply chain inventory management and the value of shared information. Manag Sci 46:1032-1048

24. Heinrich CE (2005) RFID and beyond. Wiley, Indianapolis

25. Xiao Y, Yu S, Wu K, Ni Q, Janecek C, Nordstad J (2007) Radio frequency identification: technologies, applications, and research issues. Wirel Commun Mob Comput 7:457-472

26. Veronneau S, Roy J (2009) RFID benefits, costs, and possibilities: the economical analysis of RFID deployment in a cruise corporation global service supply chain. Int $\mathrm{J}$ Prod Econ 122:692-702

27. Lee YM, Cheng F, Leung YT (2009) A quantitative view on how RFID can improve inventory management in a supply chain. Int $\mathrm{J}$ Logist 12:23-43

28. Gunasekaran A, Patel C, McGaughey RE (2004) A framework for supply chain performance measurement. Int $\mathrm{J}$ Prod Econ 87:333-347

29. Slack N, Chambers S, Johnston R (2007) Operations management, 5th edn. FT Prentice Hall, Harlow

30. Huang G, Wright P, Newman ST (2009) Wireless manufacturing: a literature review, recent developments, and case studies. Int $\mathrm{J}$ Comput Integr Manuf 22:579-594

31. Huang GQ, Zhang Y, Chen X, Newman ST (2008) RFID-enabled real-time wireless manufacturing for adaptive assembly planning and control. J Intell Manuf 19:701-713

32. Meyer GG, Främling K, Holmström J (2009) Intelligent products: a survey. Comput Ind 60:137-148

33. Brusey J, McFarlane DC (2009) Effective RFID-based object tracking for manufacturing. Int $\mathrm{J}$ Comput Integr Manuf 22:638-647 